\title{
空调制冷技术解读: 现状及展望
}

\author{
徐震原, 王如竹* \\ 上海交通大学制冷与低温工程研究所, 上海 200240 \\ *联系人, E-mail: rzwang@sjtu.edu.cn \\ 2020-02-19 收稿, 2020-03-15 修回, 2020-03-16 接受, 2020-03-17 网络版发表
}

\begin{abstract}
摘要 空调制冷已经成为人们健康、运输、食品保鲜等不可缺少的设施, 使得人们可以在地球上最冷和最热的地 方工作和生活. 本文首先分类介绍了三类典型的空调制冷技术, 其次介绍了空调除湿、热泉和低温技术的应用, 最 后总结了空调制冷技术在未来发展中所面临的能效提升、环保制冷和应用拓展等机遇与挑战. 空调制冷技术已经 成为一种基础应用技术，除传统的室内空气调节、食品药品保存和气体液化等应用以外，目前已经拓展到数据中 心冷却、电动车热管理、清洁供热、工业余热回收、低温生物医学和大科学装置中, 体现出强学科交叉融合趋势.
\end{abstract}

关键词制冷, 空调, 热葲, 低温, 冷冻冷藏

空调制冷是控制环境温度和湿度的技术，可以广 泛应用于不同领域, 并成为人们健康、运输、食品保 鲜不可缺少的设备. 由于空调制冷技术对人类生产生 活水平的显著提高, 它被评为 20 世纪最伟大的 20 项工 程技术成就之一.

由于人们对生活水平的要求和整体生产水平不断 提升, 空调制冷行业不断发展壮大, 已经发展成为一个 非常重要也非常庞大的行业. 表1所示为国际制冷学会 统计发布的全球制冷、空调和热洜运行设备数量, 总 量达到 50 亿套，其中包括26亿套空调设备和 20 亿套冰 箱冷柜，这些设备每年所消耗的电力占全球电力消耗 约 $20 \%$. 此外, 全球每年新增的制冷、空调和热㬌设备 年销售额约为 5000 亿美元，这个巨大的产业也为近 1500 万人提供了就业岗位 ${ }^{[1]}$.

从表1可以看出，空调制冷技术所涉及的应用场景 非常广, 从与人们生活最密切相关的空调、食品、医 疗健康和运动，到商业工业应用中的大型空调、热原 和低温设备, 空调制冷的应用已经渗透到了各个行业. 这一方面是基于多年发展所形成的完善空调制冷技术 体系，另一方面也是空调制冷技术本身不断与国民经
济战略需求和新兴产业相结合所取得的成效.

未来，全球气候变化、城镇化和居民生活质量提 升等诸多因素会导致空调需求更加旺盛, 全球人口增 长导致粮食需求增加和生鲜电商的快速发展, 进一步 导致冷冻冷藏需求持续增长, 深空探测、低温成像和 冷冻医疗等前沿科技的发展也会带来低温技术的不断 更新，而以上所列举的仅仅是驱动空调制冷技术发展 的部分因素. 基于以上考虑, 空调制冷技术的研究受到 众多研究者的重视, 并呈现了新的发展趋势: 空调制冷 行业的发展除了受到政策和市场等需求驱动外，还受 到前沿科学研究成果的推动, 这令空调制冷技术的发 展呈现多元化和复杂化. 在这种形势下, 对制冷空调的 技术手段和典型应用进行梳理，并对制冷空调的未来 发展进行展望是非常有必要的.

\section{1 空调制冷技术体系}

空调制冷应用广泛导致其技术体系较为复杂，相 关的技术分类也很多: 在中文术语中有空调、热洜、 普冷、深冷、低温和超低温等分类，在英文中也有 HVAC(air-conditioning)、refrigeration、heat pump和 
表 1 空调制冷运行设备数量统计 ${ }^{[1]}$

Table 1 Statistics of air-conditioning and refrigeration equipments ${ }^{[1]}$

\begin{tabular}{|c|c|c|c|}
\hline 用途 & 种类 & 设备 & 机组数量 $($ 套) \\
\hline 空调 & 固定式空调 & $\begin{array}{c}\text { 家用空调设备 } \\
\text { 商用空调设备 } \\
\text { 冷水机组 }\end{array}$ & $\begin{array}{c}11 \text { 亿 } \\
5 \text { 亿 } \\
4000 \text { 万 }\end{array}$ \\
\hline \multirow{5}{*}{ 食品冷冻冷藏 } & 移动式空调 & 车载空调(轿车、商用车及客车) & 10 亿 \\
\hline & 家用 & 冰箱和冰柜 & 20 亿 \\
\hline & 商用 & 商用制冷设备(包括冷凝机组、单机机组和商超系统) & 1.2 亿 \\
\hline & 冷藏运输 & $\begin{array}{c}\text { 冷藏车(货车、卡车、半挂车或挂车) } \\
\text { 冷藏集装箱(“冷藏箱”) }\end{array}$ & $\begin{array}{l}500 \text { 万 } \\
120 \text { 万 }\end{array}$ \\
\hline & 冷库 & 冷库 & 5 万 \\
\hline 热洜 & & 热厡(住宅、商业和工业设备, 包括冷热机组) & 2.2 亿 \\
\hline 工业制冷 & 液化天然气(LNG) & $\begin{array}{c}\text { LNG再气化站 } \\
\text { LNG油轮队(船舶) }\end{array}$ & $\begin{array}{l}126 \\
525\end{array}$ \\
\hline 健康 & 医学 & 核磁共振成像仪 & 5 万 \\
\hline 运动 & & 溜冰场 & 1.7 万 \\
\hline
\end{tabular}

cryogenics等词对应，这些分类的依据大多是根据所处 理的环境参数，并考虑了工作原理、工质和应用上的 区别. 这里借鉴了空调制冷专家联合编纂的2018 2019 年《制冷及低温工程学科发展报告》，并综合考虑了 国际制冷学会技术报告所描述的技术应用场景，将相 关技术分为制冷热洜技术、热湿控制技术和低温技术.

\section{1 制冷热原技术}

人类采用天然冰或深井水等低温物体来满足冷却 需求已具有较长历史, 这些天然冷却技术虽然有效, 但 其使用受到众多条件的限制, 无法满足人们的需求, 因 此人们开发了将热量从低温物体向环境转移的人工制 冷技术和设备. 根据热力学定律可知, 热量不会自发地 从低温状态向高温状态转移，因此人工制冷技术往往 需要消耗一些其他能量作为代价，并通常伴随着工质
热力学状态的变化. 根据产生制冷所需的不同过程, 常 见制冷技术主要包括蒸气压缩式制冷、吸收式制冷、 吸附式制冷、喷射式制冷、新兴的固态制冷和半导体 制冷等，而在这些技术中所涉及的能量转换为机械 功、电能或热能向冷能的转化.

\subsection{1蒸气压缩式制冷}

蒸气压缩式制冷是普通制冷温度下最常用的制冷 方式, 并广泛应用于空调、冷冻和冷藏等多种场景, 可 采用氨、二氧化碳、氯氟烃(chlorofluorocarbon, $\mathrm{CFC}) 、$ 氢氯氟烃(hydrochloroflurocarbon, $\mathrm{HCFC}$ )、氢 氟烃(hydrofluorocarbon, HFC) 和氢氟烯烃(hydrofluoroolefin，HFO)等多种制冷剂，其中CFC、HCFC和HFC 类制冷剂由于臭氧层破坏和温室效应已经或即将被 淘汰 ${ }^{[2]}$.

如图 1所示为蒸气压缩式制冷的原理和设备图 ${ }^{[3]}$,
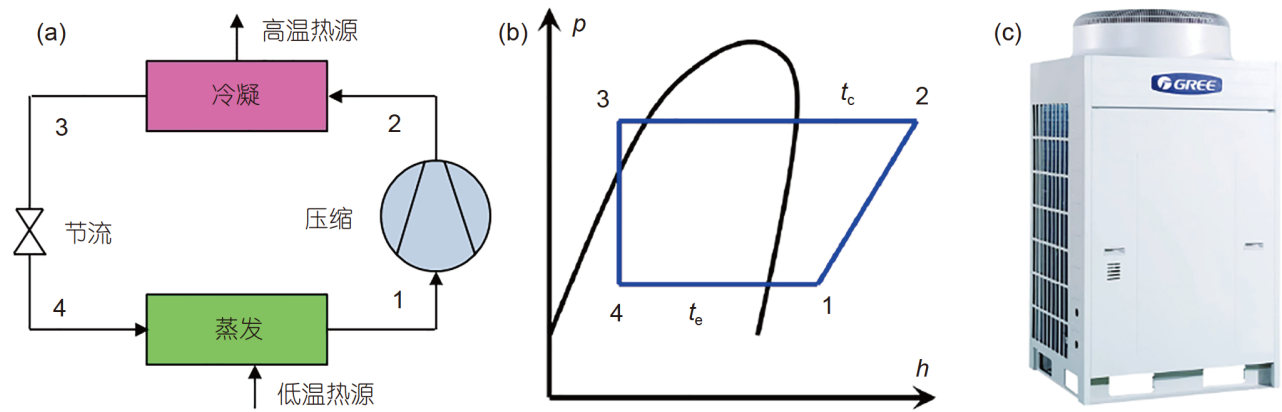

图 1 (网络版彩色)蒸气压缩式制冷. (a) 流程图; (b) 压焓图; (c) 风冷压缩式制冷机

Figure 1 (Color online) Vapor compression refrigeration. (a) Schematic; (b) $p$ - $h$ diagram; (c) air cooled chiller 
它依靠液体制冷剂的蒸发带走热量. 为了实现连续的 蒸发, 还需要配合压缩、冷凝和节流形成制冷循环: （1）低温低压制冷剂液体4吸热蒸发为低压制冷剂蒸气 1 , 该过程吸收低温热源热量, 即输出冷量; (2) 低压制 冷剂蒸气 1 被压缩为高温高压制冷剂蒸气 2 , 该过程消 耗机械功, 通常通过电能驱动压缩机完成; (3) 高温高 压制冷剂蒸气2冷凝为高压制冷剂液体 3 , 该过程向高 温热源释放热量, 高温热源通常为环境热源; (4) 高压 制冷剂液体3经过节流回到低温低压制冷剂气液混合 物4的状态. 由于驱动循环运行的过程是蒸气压缩过程, 这种制冷方式被称为蒸气压缩式制冷. 在该循环中, 低 温热源和高温热源的温度决定了蒸气在压缩前后的压 力, 进而决定了压缩过程的压力比. 当压力比适中时, 采用上述单次压缩即可, 称为单级压缩式制冷循环; 当 热源温差大导致压力比过高时，压缩机可能无法完成 所需压力提升, 此时可以采用多次压缩, 称为多级或复 叠式压缩式制冷循环. 常见的家用空调用压缩式制冷 循环性能系数(coefficient of performance, COP)为冷量 输出与电量输人的比例, 一般在 $2.0 \sim 3.5$ 之间, 热源温差 和压力比越高, 则 $C O P$ 越低.

除了采用制冷剂气液相变的蒸气压缩式制冷外, 压缩空气制冷亦获得了实际应用. 采用空气作为制冷 介质可以构建开式系统，空气经过等熵压缩和等压冷 却, 再进行等熵膨胀就形成低温冷空气, 并可以直接用 于周围环境的冷却，飞机机舱制冷即是采用了这类制 冷方式.

\subsection{2 吸收式制冷}

吸收式制冷同样依靠液体蒸发输出冷量, 但驱动 吸收式制冷循环的是热能，该驱动热能可以来自燃料 燃烧、烟气、蒸汽或热水，因此吸收式制冷可广泛应 用于太阳能制冷、余热制冷和直燃式制冷等. 吸收式 制冷采用制冷剂-溶液吸收剂的二元工质对，常用的工
质对包括应用于空调工况的水-溴化锂溶液和应用于 冷冻工况的氨-水溶液 ${ }^{[4]}$.

如图2所示为水-溴化锂吸收式制冷的工作原理和 设备 ${ }^{[5]}$, 除输出冷量的制冷剂蒸发过程外, 吸收式制冷 循环还包括制冷剂的吸收、发生、冷凝和节流过程, 其中蒸发、冷凝和节流与压缩式制冷相似，吸收和发 生过程之间通过溶液增压和节流过程耦合，并起到热 驱动的蒸气压缩作用. (1) 蒸发过程产生的低压制冷剂 蒸气被溶液吸收, 该过程产生低压浓溶液(制冷剂浓度 增加)并向环境释放热量; (2) 低压浓溶液被洜加压变为 高压浓溶液; (3) 高压浓溶液发生过程产生高压制冷剂 蒸气, 溶液则变为高压稀溶液, 该过程消耗来自高温热 源的热量; (4) 发生过程产生的高压制冷剂蒸气进人冷 凝器、节流装置并回到蒸发器，而高温稀溶液则经过 节流回到吸收器, 从而完成整个循环. 吸收式制冷是否 可以正常工作取决于热源温度，在热源温度过低无法 驱动单效循环时可以采用两级循环，而在热源温度较 高时可以采用多效循环达到更高的效率．常见的空调 用溴化锂-水吸收式制冷循环COP(冷量输出/高温热量 输人)在0.7 1.4之间, 且取决于热源温度和循环种类 ${ }^{[6]}$.

\subsection{3 吸附式制冷}

吸附式制冷与吸收式制冷相似，也是一种热驱动 的制冷技术，不同之处在于吸附式制冷采用了制冷剂固体吸附剂的二元工质对, 主要通过阀门开闭进行工 作状态的切换 ${ }^{[7]}$. 如图3所示, 通过高温热源加热吸附 床造成制冷剂的解吸, 解吸出的蒸气由冷凝器冷凝成 液体, 经过节流预冷进人蒸发器中, 蒸发器中的液体由 于另一个处于冷却状态的吸附床的吸附作用，造成蒸 发制冷. 两个吸附床加热/冷却进行切换并切换系统阀 门，可以实现连续制冷输出. 硅胶-水物理吸附、金属 氯化物-氨化学吸附是常见的两种形式, 其中水适合于 空调, 氨适合于冷冻. 由于化学吸附热一般比物理吸附 (a)

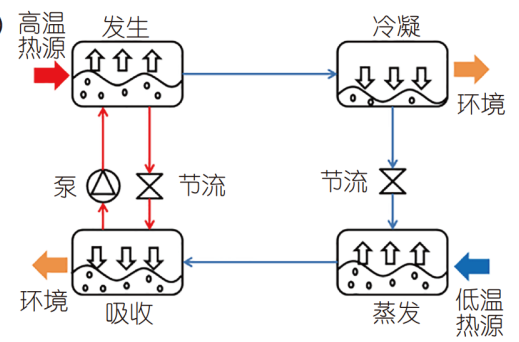

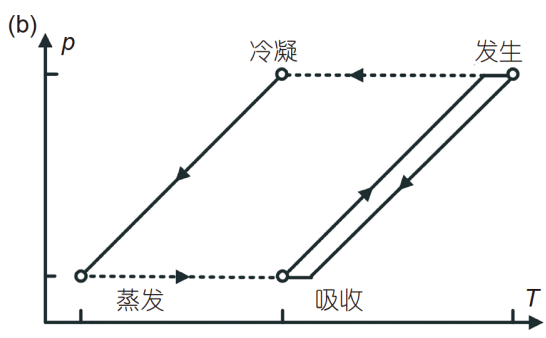

图 2 (网络版彩色)吸收式制冷. (a) 流程图; (b) 压力-温度-浓度图; (c) 单效吸收式制冷机

Figure 2 (Color online) Absorption refrigeration. (a) Schematic; (b) $p-T-x$ diagram; (c) single effect absorption chiller

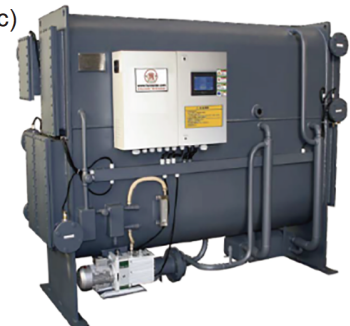



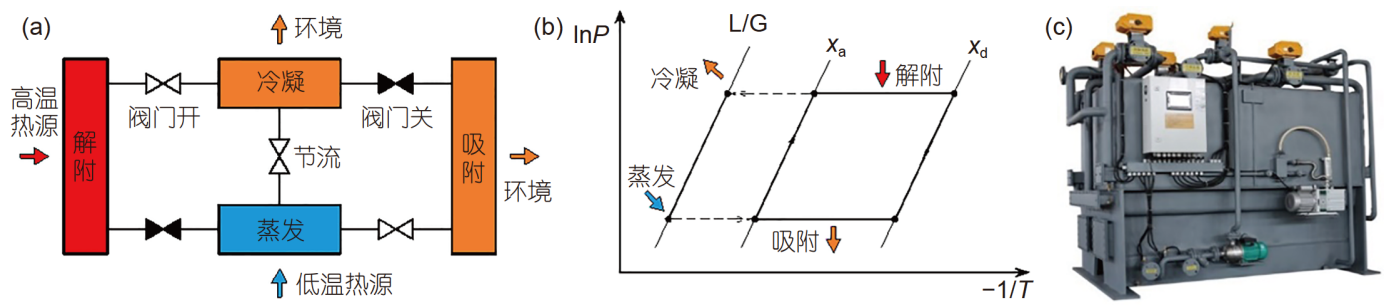

图 3 (网络版彩色)吸附式制冷. (a) 流程图; (b) 克拉伯龙图; (c) 吸附式制冷机

Figure 3 (Color online) Adsorption refrigeration. (a) Schematic; (b) Clapeyron diagram; (c) adsorption chiller

热和吸收热高，近年来化学吸附还被广泛应用于储热 过程, 并服务于太阳能热利用和余热利用, 其原理与吸 附式制冷/热葲相似.

\subsection{4喷射式制冷}

蒸气喷射式制冷也是一种热驱动制冷，与吸收/吸 附式制冷不同的是, 它仅需要制冷剂而不需要吸收/吸 附剂. 水是喷射式制冷的最常用制冷剂, 此外也有研究 采用二氧化碳、R $245 \mathrm{fa}$ 和R123等作为制冷剂 ${ }^{[7 ~ 9]}$. 喷射 式制冷主要依靠喷射器的抽吸作用产生真空效应, 促 使制冷剂蒸发从而制冷 ${ }^{[7]}$. 如图4所示为一种跨临界二 氧化碳蒸气喷射式制冷循环, 冷凝器的制冷剂液体分 为两路: 一路经过洜加压后进人发生器, 消耗高温热量 输人并变为高压制冷剂蒸气，高压制冷剂蒸气作为工 作流体进人喷射器; 另一路经过节流阀后进人蒸发器, 由于高压制冷剂蒸气在喷射器中产生的真空作用, 蒸 发器中的低压制冷剂液体蒸发并输出冷量, 而低压制 冷剂蒸气则被引射进入冷凝器. 喷射制冷还可以与蒸 气压缩式制冷系统、吸收式制冷系统等进行多种形式 的耦合, 提升系统的制冷能力.

\subsection{5 固态制冷}

压缩式制冷采用电能驱动, 并通过蒸发输出冷量,
效率高且适用范围广. 然而, 制冷剂泄漏会造成环保问 题，近年来新兴的固态工质制冷循环则不存在该泄漏 问题. 目前固态制冷主要依靠磁热、弹热和电卡效应, 通过磁场、应力场和电场的变化驱动固态制冷工质摘 的改变, 并产生热量转移的效果 ${ }^{[10 \sim 13]}$. 如图5所示为一 种主动回热式固态制冷循环的工作原理: (1) 固态磁热/ 弹热/电卡工质填充在主动固态制冷回热器(active caloric regenerator, ACR)中，在施加外场(应力场、电场、 磁场)时工质熵减小; (2) 活塞带动流体自左向右流动, 工质释放热量并被流体传递至右侧热汇; (3) 卸载外场 后, 固态工质熵增加; (4) 活塞带动流体自右向左流动, 冷量被流体传递至左侧制冷热源, 并回到初始状态. 固 态制冷具有理论效率、无运动部件和无泄漏的多方面 优势, 虽然已经出现了部分产品, 但还无法与蒸气压缩 式制冷竞争, 需要更多的基础研究与技术推进 ${ }^{[14]}$.

\subsection{6 非循环制冷}

以上制冷都依靠循环维持连续的制冷输出，除此 之外，还有部分技术可以不通过热力循环的方式产生 制冷效应, 主要包括热电制冷和新兴的辐射致冷.

热电制冷是利用塞贝克效应的逆效应——佩尔捷 效应达到制冷的技术，由于半导体的佩尔捷效应较强， (a) 高温热源 $\Rightarrow$ 发生器

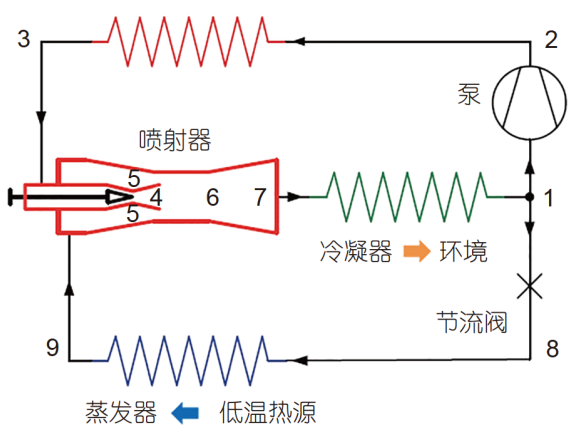

(b)

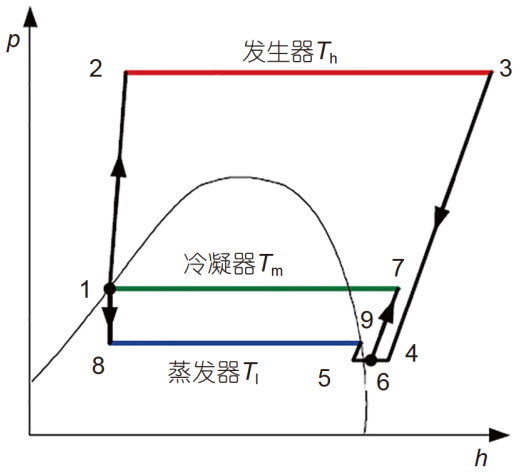

图 4 (网络版彩色)蒸气喷射式制冷. (a) 流程图; (b) 压焓图 ${ }^{[8]}$

Figure 4 (Color online) Ejector refrigeration. (a) Schematic; (b) $p$ - $h$ diagram $^{[8]}$ 


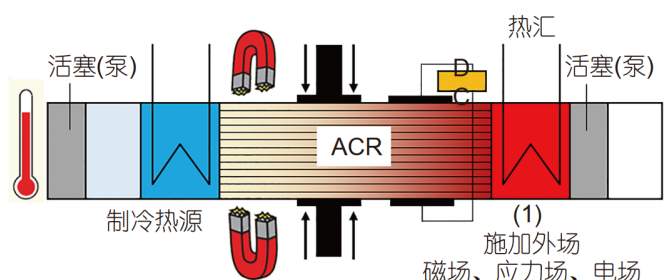

磁场、应力场、电场

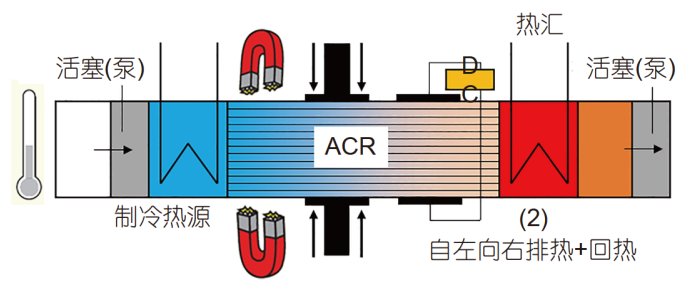

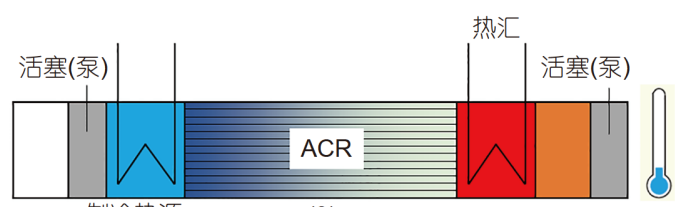

(3)

卸载外场

磁场、应力场、电场

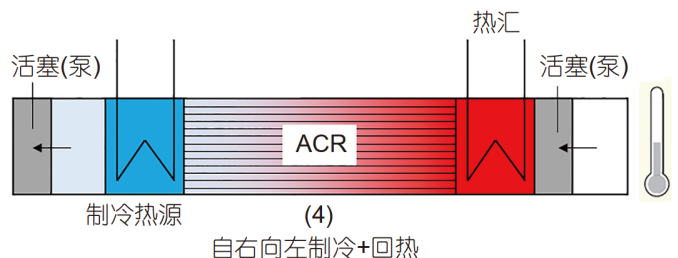

图 5 (网络版彩色)基于磁热、弹热和电卡效应的固态制冷原理 ${ }^{[15]}$

Figure 5 (Color online) Solid state refrigeration based on magnetocaloric, elastocaloric and electrocaloric effects ${ }^{[15]}$

因此热电制冷也称为半导体制冷，其制冷效率与制冷 温差和半导体材料的热电优值(thermoelectric figure of merit, ZT值)有关 ${ }^{[16,17]}$. 一对电偶的制冷量是很小的, 为 了获得较大的冷量, 可将很多电偶对串联成热电堆. 单 级热电堆可达到大约 $50^{\circ} \mathrm{C}$ 的温差, 为了获得更低的冷 端温度，可采用串联、并联及串并联的方法组合多级 热电堆. 目前半导体制冷器效率较低, 但具有体积小和 无运动部件等优点, 适用于一些特殊场合, 但在这种场 合下主要考虑制冷温度/冷量而非效率．近年来热电材 料的研究发展使得ZT值大幅提高，未来热电制冷的应 用值得关注.

辐射致冷利用辐射传热方式将热量排放到宇宙低 温背景, 从而达到制冷目的 ${ }^{[18]}$. 由于地表温度低, 辐射 致冷主要依靠红外辐射进行热量传输, 而考虑到大气 层对于红外辐射的吸收作用，仅有一部分波长范围内 的辐射可以透过大气窗口向宇宙传递能量. 在特定环 境下，上述能量输运可导致物体表面获得降温的能力, 且不需要任何外界能量驱动, 称为辐射致冷. 目前实现 夜间辐射致冷较为简单, 但由于太阳光人射的存在, 日 间辐射致冷较难，需要同时实现对可见光的高反射率 和红外辐射的高发射率. 结合新型超材料的发展, 辐射 致冷目前能够在室外完成全天候低于环境温度 $5 \sim 10^{\circ} \mathrm{C}$ 的冷却效果 ${ }^{[19,20]}$.

\subsection{7 制冷与热厡}

在常见制冷技术中，通过消耗一定的外在能量输 人, 可以从低温热源吸收热量, 并对高温热源释放热 量, 其中高温热源为环境, 因此可实现制冷效果. 在同 样的技术体系下，如果将低温热源替换为环境或其他
热能输人, 并利用对高温热源的热输出, 这种提升热能 温度的技术就称为热百. 对于市场上普遍应用的热洜 空调器, 夏季室内机起到蒸发器作用实现制冷输出, 而 冬季室内机起到冷凝器作用实现制热输出. 热原空调 机组通过四通换向阀实现室内换热器和室外换热器的 功能切换, 从而实现夏季制冷和冬季制热两种功能.

常见的热能品位提升的热洜技术包括蒸气压缩式 热洜、吸收式热洜和吸附式热洜，它们通过消耗电能 或高温热能实现对低温热能的温度品位提升，低温热 能可以来自环境或余热, 升温后的热输出可以用于供 热、生活热水或工业流程用热 ${ }^{[21]}$. 空气源热原热水器 和空气源热百供热系统均为典型的热百应用产品.

\section{2 热湿控制技术}

常见的空气调节技术主要通过调控温度和湿度实 现室内空气环境的热舒适，温度调控可以通过制冷或 热洜制热技术实现，而湿度处理方式主要包括各类除 湿技术(冷凝除湿、溶液吸收除湿、固体吸附除湿)或 加湿技术(水的直接蒸发、超声加湿等). 本质上讲, 湿 度是湿空气中水蒸气化学势能的反映，因此上述技术 的能量转换形式可以进行如下理解：冷凝除湿是通过 降低温度而降低湿度，对应“冷能 $\rightarrow$ 湿空气化学势能” 的转化; 蒸发冷却是通过增加湿度而降低温度, 对应 “湿空气化学势能 $\rightarrow$ 冷能”的转化; 而溶液吸收除湿和 固体吸附除湿则对应“吸收/吸附材料化学势能 $\rightarrow$ 湿空 气化学势能”的转化.

\subsection{1 冷凝除湿}

空气湿度有绝对湿度、含湿量和相对湿度等多种 
表示方法，其中相对湿度是影响热舒适性的重要参数, 反映了含湿量与饱和含湿量之间的比例关系. 由于空 气的饱和含湿量随温度下降而下降, 因此在含湿量不 变的情况下，通过制冷技术降低空气温度时会导致相 对湿度升高, 需要进行除湿. 当空气温度降低时, 相对 湿度会逐步升高并在露点温度下达到 $100 \%$; 如果空气 温度继续降低，相对湿度会维持在 $100 \%$, 但饱和含湿 量会继续下降, 导致空气含湿量降低, 在该过程中水蒸 气会冷凝变为液体水, 因此称为冷凝除湿.

在冷凝除湿中，压缩式制冷或吸收式制冷等技术 提供冷量, 并通过表面冷却器降低空气温度从而达到 除湿目的. 这种冷凝除湿涉及以下几个问题：(1) 由于 在冷凝除湿中空气含湿量的降低伴随着水的冷凝, 而 水的汽化潜热很高, 所以该过程需要消耗大量的冷量; (2) 由于空气的露点温度较低, 而为了达到除湿效果制 冷蒸发温度必须低于露点温度, 因此夏季空调制冷蒸 发温度需要设定在 $7 \sim 12^{\circ} \mathrm{C}$ 才能达到有效除湿, 该温度 比房间空气实际需要的制冷温度低 $15 \sim 20^{\circ} \mathrm{C}$, 从而降低 了制冷机的效率; (3) 为满足除湿需求, 空气会被冷却 到较低温度, 这种低温空气会造成室内部分区域过冷, 并影响热舒适，因此在中央空调空调箱中还需要对冷 凝除湿后的空气进行再热. 以上几个因素会导致制冷 机在处理湿负荷时能耗高，因此采用热回收装置或温 湿度独立控制等方法提升效率非常必要.

\subsection{2 溶液除湿}

溶液除湿技术采用低水蒸气分压的溶液工质作为 干燥剂, 通过直接接触吸收空气中的水蒸气, 从而达到 除湿的目的，可广泛用于温湿度独立处理、新风处 理、全热回收和工农业干燥等场景，常见的工质包括 氯化锂水溶液和溴化锂水溶液等 ${ }^{[22-24]}$. 溶液工质吸收 水蒸气的过程伴随着汽化潜热和溶质溶剂混合热的释 放, 需要冷却来维持该过程; 在溶液吸收较多水分后, 其含水量和水蒸气分压升高导致除湿能力下降，需要 通过加热再生降低其含水量并恢复除湿能力. 溶液工 质的低水蒸气分压使得该冷却过程可以通过环境作为 热沉实现, 同时也使得溶液工质再生需要高温热源, 该 热源可以来自太阳能或工业余热, 或者直接利用热洜 制冷系统的冷凝热等.

溶液除湿同时伴随着水分子和热量的转移，因此 传热传质强化非常重要. 如图6所示为一种带内冷的溶 液除湿器, 这种除湿器可以同时实现溶液与空气的高 比表面积接触、空气的流动和溶液的冷却, 具有较好
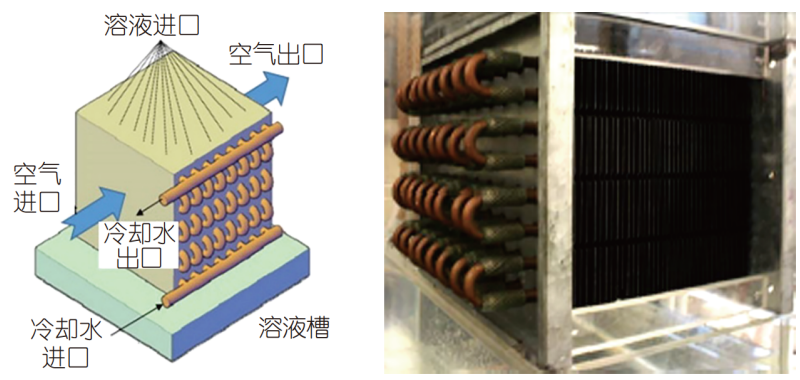

图 6 (网络版彩色)一种内冷型溶液除湿器 ${ }^{[25]}$

Figure 6 (Color online) A liquid desiccant dehumidification system with internal cooling ${ }^{[25]}$

的除湿性能. 此外, 在溶液除湿中还存在液滴夹带和抗 腐蚀等问题，可以通过溶液改性、膜除湿和特种换热 材料等方式进行改进.

\subsection{3 固体除湿}

除了采用溶液干燥剂外，固体干燥剂也可以用在 除湿中, 称为固体除湿或固体吸附除湿. 常见的固体除 湿材料包括硅胶等多孔材料以及金属氯化物等吸湿盐. 与溶液除湿相同，固体吸附剂在除湿过程中需要冷却， 且在除湿一段时间后需要加热再生, 热源同样可以来 自太阳能和余热等. 由于固体干燥剂吸湿会饱和, 需要 再生过程, 因而单个吸附床只能实现间断除湿, 而采用 两个吸附床切换可以实现连续除湿. 为了实现连续的 除湿和再生过程, 可采用如图7所示的转轮式固体吸附 除湿装置, 转轮中固体吸附材料由电机带动进行转动, 在顶部除湿后吸附材料含水量增加, 之后吸附材料转 动至底部通过热空气加热进行再生，底部吸附材料含 水量降低从而恢复其除湿能力, 恢复除湿能力的吸附 材料再转动到顶部从而进行连续除湿 ${ }^{[26,27]}$.

固体干燥剂的独特属性给固体除湿带来了挑战, 也带来了优势: (1) 由于固体干燥剂不具有溶液干燥剂

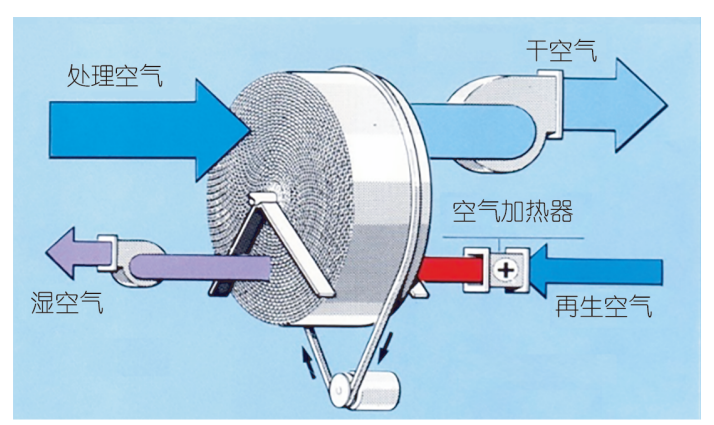

图 7 (网络版彩色)转轮式固体吸附除湿装置 ${ }^{[7]}$

Figure 7 (Color online) Rotary solid desiccant cooling system ${ }^{[7]}$ 
的流动性, 其传热传质强化更具挑战, 而在多孔导热材 料中添加吸湿盐的复合吸附剂是实现传热传质的协同 强化的重要途径; (2) 在露点温度低于 $0^{\circ} \mathrm{C}$ 的超低湿度 工况下, 冷凝除湿产生的冷凝水会出现结冰进而妨碍 进一步冷却，而选取合适材料的固体吸附除湿则不存 在这个问题；(3) 随着金属-有机骨架材料等孔径可设 计的多孔材料发展迅速 ${ }^{[28]}$, 实现 $\mathrm{S}$ 型等温吸附线、低蒸 气压吸附和超高吸附量变得可能，固体除湿技术也将 迎来新的发展机遇.

\subsection{4 蒸发冷却}

蒸发冷却技术通过水的自然蒸发吸收热量, 并带 来冷却效果, 可以分为直接蒸发冷却技术和间接蒸发 冷却. 直接蒸发冷却技术利用空气和水的直接接触进 行冷却, 冷却温度可以接近湿球温度, 形式简单, 易于 实现. 常见的开式冷却塔就是一个很好的例子, 水在空 气里的直接蒸发在相对湿度较低的工况下可以得到加 强, 因此在干燥地区效果更明显 ${ }^{[29]}$. 由于直接蒸发冷却 是等焓过程, 在降低空气温度的同时增加了湿度, 在室 内空气处理时效果不佳，在这种情况下可以采用间接 蒸发冷却技术: 通过换热器将外侧直接蒸发冷却的冷 量用于内侧空气的等湿降温 ${ }^{[30]}$.

\section{3 低温技术}

当所需冷量温度较低时，压缩式制冷和吸收式制 冷等常规制冷技术无法满足实现低温的需求，需要低 温技术进行应对. 制冷(refrigeration)和低温(cryogenics) 往往用 $123 \mathrm{~K}$ 作为分界线进行划分, 即高于该温度的范 围是制冷, 而低于该温度的属于低温 ${ }^{[3]}$. 低温技术根据
应用主要分为气体液化分离与低温制冷机技术，前者 以得到液化气体为目的, 而后者以得到低温冷量为 目的.

\subsection{1 气体液化}

气体的存储和分离往往需要气体液化, 例如气体 在冷凝为液体后体积可以大大减小从而便于存储，而 如果对多组分气体进行提纯, 也可以通过气体的液化 和精馏实现. 由于很多气体的液化温度低于或远低于 环境温度, 气体液化和分离需要达到较低温度才能实 现. 在常见的液化气体中, 空气(氧气、氮气)、甲烷、 氢气和氦气的液化最为重要.

气体液化可以通过可逆等温压缩和可逆等熵膨胀 来实现，在实际过程中，这种理想过程虽然无法实现， 但可以根据理想循环进行实际循环的构建. 如图8所示 为简单林德-汉普逊液化系统，包含等温压缩、等压降 温和等焓膨胀过程，并通过气体压缩机和焦耳-汤普逊 (Joule-Thompson，J-T)节流阀实现. 该循环是1895年德 国林德和英国汉普逊分别独立提出的一次节流循环, 是继复叠式气体液化循环后第二个用于工业上液化气 体的循环, 并可以通过预冷、双压系统和复叠式系统 提升系统性能，一般可以达到0.05 0.15的液化率和 0.05 0.25的效率. 对于氛、氢和氦的液化, 简单的节流 过程无法实现，这就需要采用低温膨胀机绝热膨胀来 辅助.

节流阀实现的是等焓膨胀，与理想的等熵膨胀相 比不可逆损失大，膨胀机等熵膨胀比节流等焓膨胀可 获得更低的温度. 如图9所示为采用了等熵膨胀的克劳 特系统, 被压缩后的气体分为两股流体, 进入膨胀机的 (a)

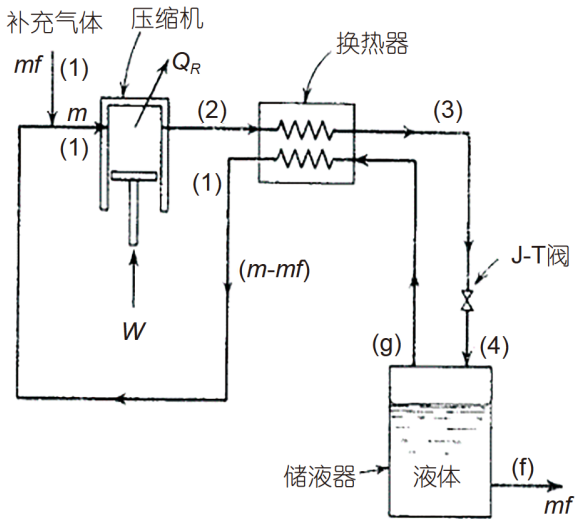

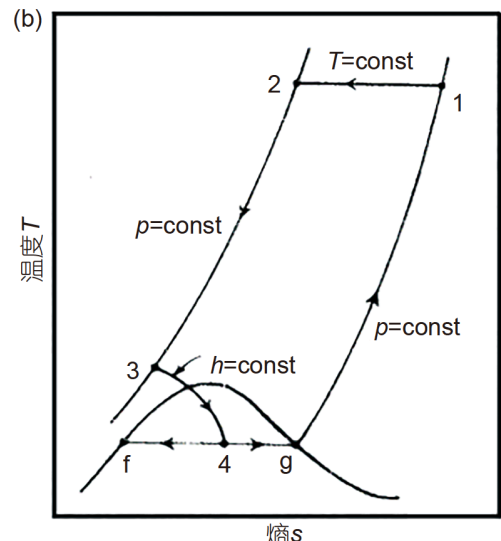

熵 $s$

图 8 简单林德-汉普逊液化系统. (a) 流程图; (b) 循环温熵图 ${ }^{[3]}$

Figure 8 Simple Linde-Hampson system. (a) Schematic; (b) $T-s$ diagram $^{[3]}$ 

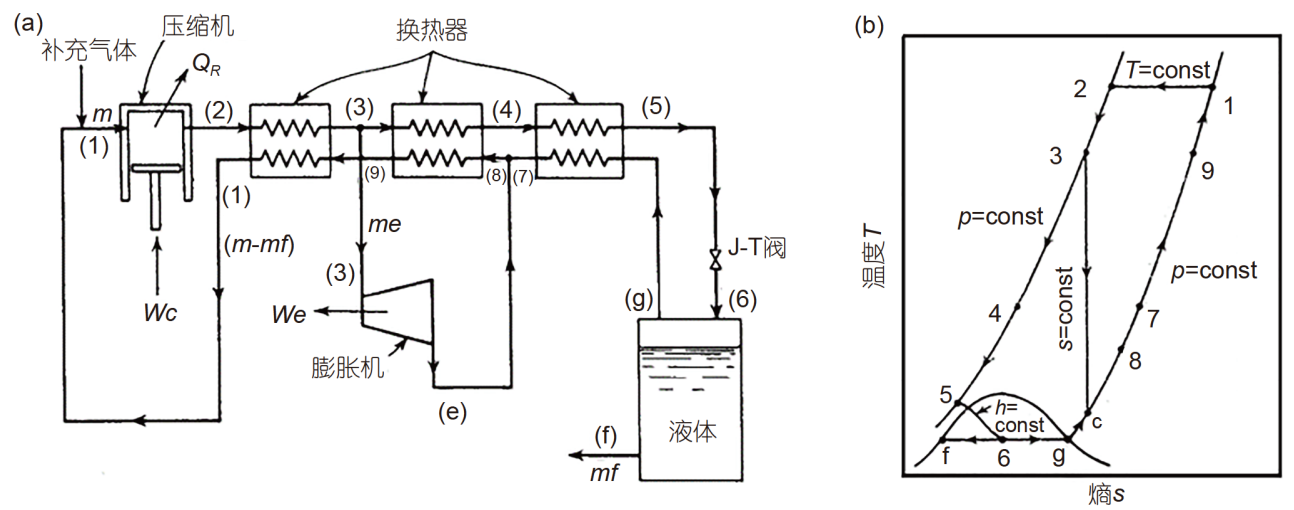

图 9 克劳特液化系统. (a) 流程图; (b) 循环温熵图 ${ }^{[3]}$

Figure 9 Claude system. (a) Schematic; (b) $T-s$ diagram $^{[3]}$

流体产生冷量并输出机械功, 进人 J-T节流阀的流体进 人气液分离器. 在克劳特系统中仍然需要 J-T节流阀产 生低压气液混合物, 其原因是实际膨胀机是不能带液 膨胀的, 但即使只有一部分气体进行了等熵膨胀, 系统 整体效率还是可以得到提升。这些系统可以达到 0.20 0.38的液化率和 $0.4 ~ 0.9$ 的系统效率.

\subsection{2 低温制冷}

低温制冷机是输出低温冷量的系统，在先进电子 系统、超导磁体和马达以及低温生物学等应用中是必 备的系统. 低温制冷系统与气体液化系统在热力循环 过程上具有相似性, 二者的区别在于: 低温制冷机产生 的是液体蒸发而带来的冷量, 属于闭式系统; 气体液化 系统产生的是液体本身, 属于半开式系统. 低温制冷机 的技术种类繁多, 根据技术的驱动和冷量输出特征可 以分为以下几类.

第一类系统依靠气体压缩机驱动，并通过蒸发过 程制冷. 这部分低温制冷机主要分为两类: (1) 焦耳-汤 姆逊制冷机. 它们都依赖于焦耳-汤姆逊效应来产生低 温. 简单林德-汉普森制冷机就属于焦耳-汤姆逊制冷 机. 它的热力循环过程与林德-汉普逊系统相同, 都包 含了等温压缩、等压降温和等焓膨胀过程，区别在于 林德-汉普逊制冷机并不从制冷机中抽走液体，而是从 低温源中吸热以蒸发液体. (2) 使用膨胀机的低温制冷 机, 包括克劳德制冷机等. 克劳德制冷机与克劳德液化 系统的热力循环相同，但同样不从制冷机中抽走液体， 而只利用制冷剂蒸发过程输出冷量.

第二类系统依靠气体压缩机驱动, 并通过气体等 温膨胀过程制冷, 主要包括斯特林制冷机和维尔米勒 制冷机. (1) 斯特林制冷机包括气体的等温压缩、等容
降温、等温膨胀和等容升温过程 ${ }^{[31]}$, 其中等温压缩过 程需要外界机械功输人和环境冷却，等温膨胀过程输 出冷量, 而等容降温和等容升温之间需要进行回热且 对系统性能十分重要, 其热力学过程如图10(a)所示. (2) 维尔米勒制冷机属于热驱动压缩与斯特林制冷的 耦合, 其中热驱动压缩子循环采用气体为工质, 在高温 热源与中温热源之间工作并输出机械功, 该机械功用 于驱动斯特林制冷子循环的压缩过程.

第三类系统依靠气体压缩机驱动，并通过气体等 压升温过程制冷, 主要包括索尔凡制冷机和吉福特一 麦克马洪(Gifford-McMahon, GM)制冷机. 这两种制冷 机的理想过程包括气体的等温压缩、等压降温、等熵 膨胀和等压升温，其中等温压缩过程需要外界机械功 输人和环境冷却, 等压升温的低温段用于冷量输出, 等 压升温的高温段用于冷却等压降温过程, 其热力学过 程如图10(b)所示. 在索尔凡制冷机中，等熵膨胀过程 对外做功; 在 $\mathrm{GM}$ 制冷机中, 膨胀过程中没有对外功输 出, 而是用于内部气体的移动, 在回热器中无压降的理 想情况下气体转移过程的净功为零. 尽管索尔凡制冷 机比GM制冷机的效率高, 但GM制冷机的位移器处泄 漏少且驱动结构简单, 并可以通过多级化实现高效的 低温制冷.

第四类系统是脉冲管制冷，它省去了诸如斯特林 和 $\mathrm{GM}$ 等常规气体制冷机中的冷腔膨胀活塞, 采用一根 低热导管子来代替，从而在管子内产生很大的温度梯 度, 以实现制冷效果. 脉冲管制冷机从根本上解决了冷 腔振动、密封、磨损和难以加工等问题, 具有结构简 单、运转可靠、冷头振动小、寿命长和成本低等优势. 除了基本型脉冲管制冷机，还有小孔型脉冲管制冷 

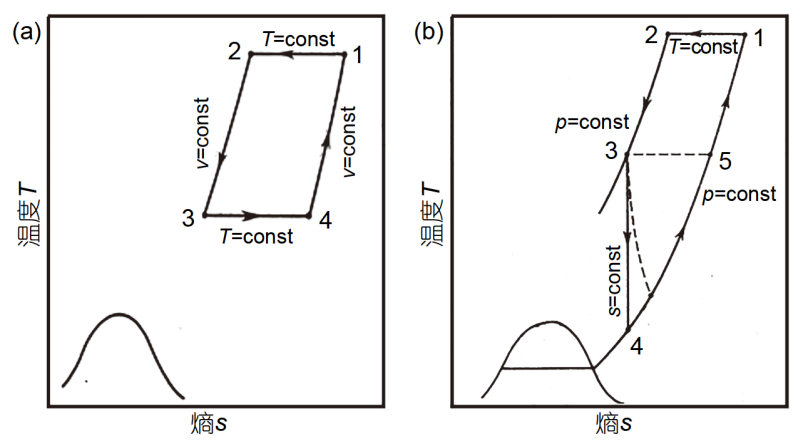

图 10 低温制冷机温熵图. (a) 斯特林制冷机; (b) 索尔凡制冷机 ${ }^{[3]}$ Figure $10 \quad T-s$ diagram of cryocooler. (a) Stirling cryocooler; (b) Solvay cryocooler ${ }^{[3]}$

机、多路旁通脉冲管制冷机、双活塞脉冲管制冷机、 四阀式脉冲管制冷机和多级脉管制冷机等多种形式. 通常脉冲管制冷机采用的工质为氦气，但为了获得更 低的温度, 也可采用氦-3作为工质并获得 $1.78 \mathrm{~K}$ 的低温.

除了以上介绍的几种系统外，常见的低温制冷机 还包括热声制冷机和吸附式低温制冷机，这两种制冷 机属于热驱动低温制冷. 热声制冷机依靠热声驱动器 驱动谐振管内气体产生绝热压缩和膨胀, 并产生制冷 作用, 可以和脉冲管进行结合 ${ }^{[32]}$. 吸附式低温制冷机则 利用吸附床产生压缩和真空作用，并配合J-T节流阀产 生制冷作用，可采用氢气、氧气、氩气、甲烷和氮气 等作为制冷剂，其中基于金属吸氢材料-氢气的化学吸 附制冷方式可以获得液氢低温，甚至通过升华作用可 获得低达 $7 \mathrm{~K}$ 的温度.

以上讨论的这些低温制冷机采用液体或气体作为 工质, 而当温度低于 $0.6 \mathrm{~K}$ 时大部分材料为固体, 只能用 液氦-4或液氦-3减压蒸发达到低于 $0.6 \mathrm{~K}$ 的低温. 在温 度为 $0.6 \mathrm{~K}$ 时, 液氦 -4 和液氦 -3 的蒸气压分别为 $37.5 \mathrm{mPa}$ 和72.6 Pa, 而维持这种低压亦十分困难, 导致这类系统 实际所能得的温度下限为 $0.4 \mathrm{~K}$. 为了解决超低温范围 内的冷量输出, 可采用磁制冷和稀释制冷机: 低温磁制 冷与前述固体制冷原理一样, 通过磁场影响顺磁物质 的熵变, 从而代替流体的膨胀得到低温, 并获得 $\mathrm{mK}$ 级 的低温; 稀释制冷机则通过超流氦 -4 稀释氦 -3 的办法制 冷, 并可以获得 $0.005 \mathrm{~K}$ 的低温.

\section{2 空调制冷技术的应用}

空调制冷技术可以调控温度和湿度两个非常重要 的环境参数, 因此具有广泛的应用, 如空气调节、清洁 供热、冷冻冷藏、能源利用、余热回收、生物医学和
科学装置等.

\section{1 制冷除湿技术应用}

\subsection{1 空气调节}

空气调节是空调制冷技术最常见的应用，主要涉 及温湿度的调控，一般特指降温除湿过程，可用于民用 和商用场合, 目的是满足人体对热舒适性的需求, 近年 来其应用也拓展到了对档案室和图书馆等场所的应用. 空调技术的发展显著提升了人们的生存条件. 研究表 明，美国在 20 世纪将平均温度超过 $27^{\circ} \mathrm{C}$ 的天气对死亡 率的影响下降了约 $75 \%$ ，该下降趋势在1960年后尤为 明显, 而家用空调的普及从本质上解释了这种现象 ${ }^{[33]}$. 随着相关技术的发展, 空调成本在不断降低, 普及率也 在不断上升. 统计数据显示, 我国每百户空调拥有量已 达到115.6台，导致用电量巨大；按照国际能源署IEA统 计, 空调用电量占全球总用电量的 $10 \%{ }^{[34]}$, 这也表明空 调已经成为人们生活中必不可少的部分.

由于空气调节涉及普冷范围的降温和湿度控制, 因此主要技术包括压缩式制冷、吸收式制冷和吸附式 制冷等制冷技术和冷凝除湿、溶液除湿、固体吸附除 湿和蒸发冷却等热湿环境控制技术. 由于电网电力的 普及, 压缩式制冷配合冷凝除湿是最常用的技术, 包括 窗机空调、分体式空调和中央空调等多种形式，此外 汽车空调绝大部分也是采用的压缩式制冷技术.

\subsection{2 数据中心冷却}

数据中心是电子信息产业的重要场所, 随着 $5 \mathrm{G}$ 通 信、物联网和人工智能等应用的快速发展，数据中心 的数量和体量也飞速发展, 导致其耗能严重. 数据中心 能耗根据用途分为IT设备能耗和辅助系统能耗两大类: IT设备主要包括服务器、交换机等; 辅助系统有空 调、配电系统等. 目前, 空调系统仍然是数据中心的主 要能耗系统, 占数据中心总功耗的 $40 \%$ 左右.

数据中心主冷却与室内空气调节不同点在于: (1) 数据中心主冷却对新风需求少, 热负荷较多, 而湿负荷 较低; (2) 数据中心冷却需要在一年四季运行; (3) 数据 中心的温度较室外环境往往更高. 基于以上原因, 在采 用压缩式制冷等主动制冷技术达到降温目的之外，通 过自然冷却和传热强化等过程将热量直接排放到室外 环境中也是重要的技术手段 ${ }^{[35]}$. 此外, 包括 $\mathrm{CPU}$ 等部件 运行温度可高达 $60^{\circ} \mathrm{C}$ 以上, 这部分热量可以用来驱动 吸附式制冷机并产生冷量, 而冷量又可以用于机房降 温, 从而实现余热的自产自销 ${ }^{[36]}$. 


\subsection{3太阳能制冷}

可再生能源的利用对人类的可持续发展至关重要. 在众多可再生能源中, 太阳能是目前使用最广泛的, 将 太阳能与制冷技术结合起来可以有效地缓解空调制冷 对能源消耗严重的问题 ${ }^{[37]}$. 由于太阳能的利用分为光 伏和光热两种主要技术，所以太阳能制冷也分为太阳 能光伏制冷和太阳能光热制冷.

在太阳能光伏制冷系统中, 太阳能光伏板为蒸气 压缩式制冷机提供电源, 为解决太阳能的不稳定性和 间歇性可配备电池作为储能装置, 也可以采用来自电 网的电作为替补驱动能源, 最后得到连续稳定的制冷 输出. 由于太阳能光伏板供给直流电, 而蒸气压缩式制 冷机需要交流电驱动, 因此一般还需要逆变器将直流 电转换为交流电. 近年来太阳能光伏直流直驱空调系 统也已经面世, 由于中间少了电力直流/交流的转换, 空调系统效率可以提升 $15 \%$ 20\%.

在太阳能光热制冷系统中, 太阳能集热器为吸收 式或吸附式制冷机提供热源, 为解决太阳能的不稳定 性和间歇性可配备水箱等储热装置, 也可以采用燃气 锅炉作为替补驱动能源, 最后得到连续稳定的输出. 在 太阳能光热制冷中存在太阳能热源温度与吸收吸附式 制冷机的温度匹配问题，例如平板式集热器可提供 $100^{\circ} \mathrm{C}$ 以下的热水，所以与单效溴化锂-水吸收式制冷 机或硅胶-水吸附式制冷机匹配; 槽式集热器可以提供 $150^{\circ} \mathrm{C}$ 以上的热源, 可以与双效溴化锂水吸收式制冷机 或氨水吸收式制冰机匹配.

\subsection{4 电动车热管理}

受节能环保政策的大力推动, 电动车成为新能源 产业的重要支柱, 并在我国得到快速发展. 由于电动车 以电池作为储能装置, 其面临了两方面的问题: 首先电 池只能在一个比较窄的温度范围内高效工作，所以其 热管理对有效供能十分重要; 其次电池的储能密度比 汽/柴油低, 且电池成本昂贵, 因此采用电池驱动的空 调系统设计需要进行优化 ${ }^{[38]}$.

电动车的电池热管理技术包括冷却与加热两方面: （1）电池的传热较差, 导致电池温度容易升高, 而高温 不但会带来电池寿命的衰减, 还带来了安全隐患, 必须 通过电池冷却防止电池温度过高. 电池冷却技术包括 空气冷却、液体冷却和热管冷却等, 其复杂度和效果 依次递增. (2) 常用动力电池在 $-20^{\circ} \mathrm{C}$ 时, 其可用放电容 量仅能保持常温的 $30 \%$ 左右, 因此在低环境温度下有必 要提升电池温度, 以保证其工作效率. 电池加热技术包
括循环高温气体加热、循环高温液体加热和加热板/膜 类加热法等.

电动车空调系统主要是为了提升驾驶舒适性, 但 由于空调系统的能源同样来自电池, 空调系统运行对 电动车续航里程影响很大. 根据研究, 电动车夏季制冷 消耗可导致续航里程下降 18\% 53.7\%; 冬季暖风消耗 更可以导致续航里程下降 $60 \%$ 以上，其主要原因在于 冬季暖风以电阻加热器提供, 效率比夏季空调工况低 很多. 为了解决电动车冬季暖风消耗过高的问题, 可以 采用空气源热泵的形式提升效率，但同样存在低环境 温度下的高效运行挑战, 空气源电动热百化霜也是其 面临的另外一个难题.

\subsection{5 食品药品保存}

冷冻冷藏技术对于粮食、食品和药品的保存都非 常重要. 冷冻冷藏缺失所造成的全球食品损失占全球 食品供应的 $20 \%$; 市场上每 2 种药品中就有 1 种是热敏 性药品, 而很多热敏性药品需要在 $2 \sim 8^{\circ} \mathrm{C}$ 之间保持. 此 外, 疫苗有效性也非常依赖适宜温度的保存. 保鲜技术 除了可以提升食品的风味, 还可有效抑制细菌和有毒 病原体的生长, 预防食源性疾病 ${ }^{[1]}$. 在我国, 每年易腐 食品的总调运量达 3 亿多吨, 综合冷链流通率仅为 $19 \%$, 果蔬、肉类和水产品的流通腐损率分别达到 $20 \%$ $30 \% 、 12 \%$ 和 $15 \%$, 造成了巨大的损失. 可以看出, 冷冻 冷藏对于食品行业是不可或缺的.

冷链装备是冷链物流体系的核心, 是冷链物流的 基础设施，在易腐食品加工、保鲜、储运、销售、信 息可追溯、食品安全等领域发挥着重要作用, 直接影 响到环境、能源、食品价格、食品品质, 是冷链物流 绿色可持续发展的关键. 近年来, 随着我国对食品安全 和食品品质的重视, 冷链装备技术亦成为研究热点, 新 技术和新产品不断涌现. 冷冻冷藏所涉及的温度范围 比空调更宽, 除了高于零度的冷藏, 更多的涉及低于零 度的冷冻. 对于大多数冻结食品来讲, $-18^{\circ} \mathrm{C}$ 是最经济 的冻藏温度. 表 2 给出了冷链各环节涉及制冷技术的冷 链装备和相关技术，除了采用有机制冷剂、氨和二氧 化碳的压缩式制冷机提供冷量外, 冷冻冷藏更多涉及 的是冷量与食品之间的相互作用 ${ }^{[39,40]}$.

\section{2 热㫤技术应用}

\subsection{1 高效清洁供热}

采暖、生活热水和工业流程等过程均需要供热技 术支撑. 统计年鉴显示, 我国仅集中供热在2018年就消 
表 2 冷链环节中的冷链装备

Table 2 Equipments in different sectors of cold chain

\begin{tabular}{|c|c|c|}
\hline \multicolumn{2}{|c|}{ 冷链环节 } & 冷链装备 \\
\hline 冷加工 & 预冷 & 压差预冷、冰预冷、真空预冷、冷水预冷 \\
\hline & 速冻 & 空气强制循环、接触式、喷淋浸渍 \\
\hline 冷冻冷藏 & & 氨制冷系统、制冷系统、 $\mathrm{CO}_{2}$ 制冷系统 \\
\hline 冷藏运输 & & $\begin{array}{c}\text { 机械式冷藏车、一次性冷能冷藏车、 } \\
\text { 蓄冷冷藏车 }\end{array}$ \\
\hline 冷藏销售 & & 商用冷藏柜、商用冷冻柜、生鲜配送柜 \\
\hline
\end{tabular}

耗了 3.8 亿吉焦的热量 ${ }^{[41]}$, 而没有集中供热的北方地区 和长江中下游地区则只能利用分散式的锅炉或普通热 洜空调供热, 存在排放严重或热舒适性差的问题. 清洁 供热是指采用清洁能源满足热需求的技术，是针对传 统供热采用煤炭燃烧导致污染和排放严重所提出的, 也受到“煤改电”“煤改气”等政策的大力推动, 是近年来 在节能减排政策推动下的新兴发展领域. 相比电加热 取暖, 热百供热可以利用一部分环境热源的热量, 所以 效率要比电加热更高, 运行成本也更低.

热原技术以蒸气压缩式热洜为主，吸收式热洜为 辅. 根据低温热源来源, 热洜可以分为水源热洜、地源 热源和空气源热葲，这几种热葲分别从河水/海水、土 壤和空气提取热量并通过热葲提升温度用于供热. 相 比于水源热洜和地源热洜, 空气源热洜不需要抽取地 下水或配置地埋管等, 安装和使用都比较方便, 因此在 我国北方煤改电供热中获得了快速推广。压缩式空气 源热葲除了应用于热水器, 还可以与供暖末端结合为 室内供热. 由于空气源热原市场很大, 相关技术研发也 得到了快速发展，多级热㫤、中间补气增焓和小温差 换热末端等技术应运而生，目前空气源热泵效率已经 达到较高的水平, 并可以在我国最寒冷的地区使用. 吸 收式空气源热百一般采用燃气燃烧或中温太阳能热源 驱动，由于冬季向空气吸热的过程往往发生在零度以 下, 因此吸收式空气源热葲采用氨水工质对.

空气源热百不仅在民用供热展现出了强劲的优势, 而且在物料/药品干燥或大棚冬季控温等方面也获得了 应用, 但是工业应用还比较少, 其主要原因在于当前的 热葲技术在高温输出和大温升工况下效率及稳定性还 有所欠缺.

\subsection{2 工业余热回收}

统计年鉴显示，我国能源加工转换中的余能占全 国总能耗的 $26.3 \%$, 而余能的绝大部分是热能. 如果回
收余能中的 $50 \%$ 并加以利用, 则可以将社会总能耗降低 至 40.3 亿吨标煤 ${ }^{[41]}$. 常见的余热回收方式主要包括余热 直接利用、余热发电、余热制冷和热洜余热利用.

在工业余热中, 低于 $150^{\circ} \mathrm{C}$ 的低品位余热体量巨大, 在钢铁、水泥和玻璃等行业甚至占到总体余热的约 $50 \%$. 例如, 工业流程需要通过冷却塔排放低于 $50^{\circ} \mathrm{C}$ 低 品位余热, 不仅造成能源浪费, 还需要消耗额外水资源 和电力维持冷却塔运行，回收这部分余热的意义十分 重大 ${ }^{[42]}$. 余热发电和余热制冷技术在针对超低品位余 热利用时效率低且应用场合有限，因此热葲技术成为 回收低品位工业余热的最佳选项.

采用热洜回收工业余热的技术主要包括蒸气压缩 式热原和吸收式热洜，吸收式热百又分为增量型的一 类吸收式热洜和升温型的二类吸收式热葲。蒸气压缩 式热百和一类吸收式热百输出温度大多在 $100^{\circ} \mathrm{C}$ 以下, 二类吸收式热葲的输出温度则可以达到 $150^{\circ} \mathrm{C}$ 以上, 其 热输出可广泛应用于供热、干燥、精馏和蒸汽发生等 过程 ${ }^{[21,42]}$. 如图11所示, 由于热百的热输出温度越高, 在 工业流程中的可用性越强，因此输出温度高的热泵技 术在工业余热回收中具有广泛前景. 近年来, 研究者也 针对高温热泉展开了诸多研发, 出现了包括水蒸气压 缩式热原等新型高温热原技术 ${ }^{[43]}$, 并可以达到 $150^{\circ} \mathrm{C}$ 的 高温输出，为热洜在工业余热回收的进一步拓展奠定 了基础.

\section{3 低温技术应用}

\subsection{1 液化气体}

液化气体的应用是非常广泛的，工业流程所需要 的液氮或纯氧通常需要通过气体液化分离技术提供.

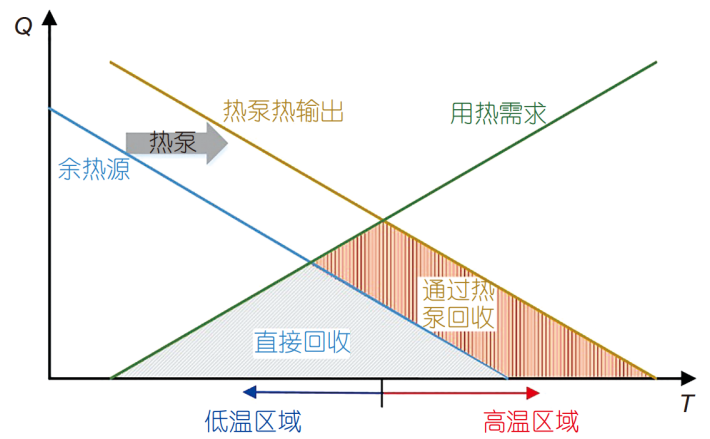

图 11 (网络版彩色)余热和工业用热需求体量随温度变化的简化示 意图 ${ }^{[42]}$

Figure 11 (Color online) Simplified $T-Q$ diagram of the waste heat and industrial heating demand ${ }^{[42]}$ 
除此之外, 液化天然气和液氢等重要能源供应也依赖 气体液化技术.

天然气是当前能源结构下的重要能源形式. 根据 最新统计年鉴, 我国的能源消费中天然气的比例从 2008年的3.2\%增长到2018年的 $7.8 \%$ ，按照能量消费总 量更是在这 10 年间从1.1亿吨标煤增长到 3.6 亿吨标煤, 是仅次于煤炭和石油的重要能源形式 ${ }^{[41]}$. 由于天然气 在常温常压下是气体状态, 与煤炭和石油相比, 天然气 的运输更具挑战, 而天然气的体积在液化后可缩小到 原来的 $1 / 600$ 左右, 大大方便了它的储存和运输. 常规 液化天然气主要依靠单一工质蒸气压缩式制冷循环、 混合工质蒸气压缩式制冷循环、气体膨胀制冷循环等 几种基本循环以不同方式复叠而成的高效液化流程生 产出来. 近年来, 包括页岩气等非常规天然气的大量发 现也推动了贫气液化、煤层气液化、含氢甲烷液化、 天然气带压液化和小型琵装液化装置等非常规天然气 液化技术的发展 ${ }^{[44 ~ 46]}$.

氢气作为可从多种途径获取的理想能源载体, 具 有来源广泛、污染少且能量密度高的优势, 是化石能 源向可再生能源过渡的重要桥梁. 氢能利用需要解决 制取、储运和应用等一系列问题, 而氢气密度低导致 的储运效率低是影响氢能应用的重要因素. 用液氢作 为储运方式, 不仅便于咜存和远距离运输, 还能得到高 纯氢气, 可满足半导体、医药、食品等加工生产的需 要 ${ }^{[47]}$. 根据液化规模的大小, 相应的氢气液化技术也会 发生变化, 液化率低于 $100 \mathrm{~L} / \mathrm{h}$ 的一般采用J-T节流, 液 化率在100 3000 L/h的一般采用氦膨胀制冷, 而液化率 高于 $3000 \mathrm{~L} / \mathrm{h}$ 的一般采用氢膨胀制冷.

\subsection{2 低温生物医学}

低温制冷技术与生命科学的结合形成低温生物医 学技术, 这类技术既可以用于保护或保存生物活体, 也 可以对生物活体进行破坏或者治疗. 低温生物医学技 术与低温保存、冷冻干燥、低温医疗、基因等领域密 切相关, 主要涉及生物样本低温保存和低温医疗装备.

进行低温保存的生物样本种类主要包括血液制品 保存 $\left(4^{\circ} \mathrm{C},-20^{\circ} \mathrm{C}\right)$ 、干细胞保存 $\left(4^{\circ} \mathrm{C},-80^{\circ} \mathrm{C}\right)$ 、人类生 殖细胞保存 $\left(-196^{\circ} \mathrm{C}\right)$ 、种质资源保存 $\left(-80^{\circ} \mathrm{C},-196^{\circ} \mathrm{C}\right)$ 、 组织工程材料保存 $\left(-196^{\circ} \mathrm{C}\right)$ 以及临床医学样本保存 $\left(-80^{\circ} \mathrm{C}\right)$ 等, 不但涉及普冷范围的冷冻冷藏, 更多涉及 的是低温保存.

低温医疗作为生物医学工程学领域内的一门新兴 的交叉学科, 是近年来涌现出的一种相当有效的物理
疗法, 其原理在于: 通过低温治疗疾病, 改善机体功能, 促进人体健康. 冷冻手术是一种操作方便、价格低廉 且只需简单设备的技术，它在治疗皮肤癌方面的成功 率高达 $99 \%$, 在治疗女性低风险乳腺癌方面的成功率 高达 $99.4 \%$. 核磁共振成像在医学诊断中有着广泛应 用, 有助于医生对人体内部深层结构进行细致观察, 而 超导是核磁共振成像扫描仪维持强稳定磁场的核心 ${ }^{[1]}$, 超导体的正常维护运行必须获得低温的保障.

\subsection{3 大科学装置}

维持低温是很多大科学仪器的必备条件, 在深空 探测、量子芯片、可控核聚变、同步辐射光源、自由 电子激光和大型强子对撞机等装备上都有所应用. 例 如在深空探测中, 宇宙背景温度极低, 要对该低温背景 下的天体进行精准观测就必须提高探测灵敏度和稳定 性，而维持空间望远镜和相关设备的低温状态是其基 础; 在量子芯片中，同样需要将芯片冷却到 $\mathrm{mK}$ 级别的 温度才能维持正常运行; 在可控核聚变和大型强子对 装机中, 超导是维持系统运行的条件, 而液氦温区低温 又是实现超导的基础 ${ }^{[4850]}$. 现在已经建成的基于低温 技术的大科学工程有处于瑞士/法国的大型强子对撞机 (Large Hadron Collider, LHC)、美国的托克马克聚变试 验堆(Tokamak Fusion Test Reactor, TFTR)和散裂中子 源(Spallation Neutron Source, SNS)、北京的正负电子 对撞机(Beijing Electron Positron Collider, BEPC-II), 此 外还包括上海光源二期、国际热核聚变实验堆和欧洲 散裂中子源等很多在建装置, 这些装置也将为人类探 索基础科学提供更多的实验证据.

\section{3 空调制冷技术的挑战}

空调制冷已经具有大而全的技术体系, 并已经成 为众多行业及新兴产业的支撑技术. 目前我国经济发 展已经从体量增加转变向质量提升, 对可持续发展和 高新技术的需求越来越多, 在这种情况下, 空调制冷技 术也面临着新的压力和挑战. 受到节能环保需求影响, 制冷空调技术仍然面临着较大的技术革新压力. 根据 国际制冷学会的估算, 与制冷行业相关的碳排放约为 $4.14 \mathrm{Gt}$ 二氧化碳当量, 占全球温室气体排放的 $7.8 \%$, 这些对于全球变暖的影响 $37 \%$ 来自含氟制冷剂 (CFCs、HCFCs 和HFCs)的排放或泄漏，其余63\%来自 制冷系统所需电力在发电过程产生的间接排放 ${ }^{[1]}$. 为 此, 制冷空调行业需要进一步提高制冷设备的能效, 进 一步降低制冷剂对环境的破坏效应. 总的来说, 空调制 
冷技术未来将在以下几个方向得到长足的发展.

\section{1 能效提升}

能效提升的方式主要有部件性能提升和系统改进 两个方面, 部件提升方面主要包括换热器和压缩机的 提升，而系统改进则包括流程改进、热力循环创新以 及运行控制优化等.

换热器是空调制冷系统的重要组成部件, 它造成 的换热不可逆损失是导致空调效率下降的重要原因之 一. 小管径的翅片换热器、点波波纹板板式换热器、 印刷板路换热器等新型换热器可以显著提升换热效 率 $^{[11,52]}$. 压缩机是蒸气压缩式系统的核心部件, 它通过 电机带动蒸气压缩过程, 因此其性能提升也包括提升 电机效率和提升蒸气压缩效率两方面.

流程改进主要包括通过增强循环内部回热降低循 环内不可逆损失，以及通过内部流程与外部热源之间 的匹配降低外不可逆损失，涉及温度梯级利用和换热 过程匹配等方法. 热力循环创新则更加强调对新热力 学过程的加人以改变原有循环架构, 难度大, 但效果往 往也很好.

在热力学循环形式确定的情况下，提升换热器性 能、压缩机性能和内外热回收是提升空调制冷系统效 率的有效方式, 但也存在着显著的边界效应：当换热器 和压缩机性能提升到一定程度后，进一步的提升难度 加大，系统成本上升，但总体效率增加缓慢；当内外回 热提升到一定程度后，进一步的回热提升会显著增加 系统复杂度, 造成系统控制复杂且成本上升, 但系统总 体效率提升缓慢. 在这种情况下, 通过另起炉灶的方式 打破原有热力学循环方式是实现系统效率显著提升的 有效途径.

运行控制优化是利用人工智能技术对空调制冷系 统进行运行优化, 降低系统能耗, 这在空调系统中特别 有效. 云平台和大数据可以反馈给空调系统设计, 从而 获得与实际运行需求更加切合的空调产品. 仿生热学 和仿生材料学与空调系统相结合可以为下一代更高能 效、更加舒适的空调系统提供新的思路和解决方案.

\section{2 环保制冷}

含氟制冷剂的泄露会带来温室效应和臭氧层破坏 效应. 为了降低这种环境破坏效应, 环保制冷主要可以 从两方面着手：首先是使用低全球增温潜势 (global warming potential, GWP)和低臭氧破坏潜势(ozone depletion potential, ODP)的制冷剂, 其次是减少制冷剂的 充注量和有效降低制冷剂的泄露.

替代制冷剂是空调制冷行业近年来的热点话题, 也是推动行业未来发展的重要政策因素. 传统的制冷 剂R22虽然性能理想，但其GWP和ODP较高已经被淘 汰. 目前常用的空调制冷剂R134a和R410a也将在不久 的未来被淘汰。新型 $\mathrm{HFO}$ 类替代制冷剂 R1234yf、 R1234ze(E)、R1234ze(Z)和R1233zd(E)等目前受到广 泛关注，水、氨和二氧化碳等天然工质也一直是热点 话题，但这些制冷剂仍然面临着压力过高或过低、安 全性和传热传质性能差等挑战 ${ }^{[3]}$.

除了使用低GWP和低ODP的制冷剂外，减少制冷 剂泄漏量也是可行的技术路线，因此采用微通道换热 器降低空调制冷系统的充注量是很有潜力的方向. 此 外, 由于新型HFO制冷剂具有可燃风险, 降低充注量也 会使其可燃性变得可控. 由于微通道换热器的流动传 热强化机理与常规换热器有所不同，同时涉及微细加 工工艺, 其设计生产成本偏高, 需要高校和企业在未来 共同努力推动其广泛使用.

\section{3 应用拓展}

空调制冷技术的传统应用包括室内空气调节、冷 冻冷藏、液化气体和低温制冷机等方面，然而上文所 介绍的应用已经远超出了该范围，数据中心冷却、太 阳能制冷、电动车热管理、高效清洁供热、工业余热 回收、低温生物医学和大科学装置等诸多应用都是与 新兴产业息息相关的. 其原因在于, 空调制冷技术已经 慢慢变为一种基础应用类技术，它为不同行业的发展 提供支撑，同时也配合国家发展需求而不断改进.

传统的空调制冷技术已经较为成熟，但在应用于 新兴领域时仍然需要进一步提升. 例如, 输出温度高和 温度提升能力强的热㬌技术必然会对进一步拓展余热 回收起到重要作用，但传统制冷空调技术对于高温热 原的技术积累仍然不够多，所以还需要高温热原的制 冷剂、热力循环、换热技术和控制技术进行深人研究. 又如, 传统的空调热洜技术由于要满足除湿要求, 蒸发 温度低, 系统效率低且热舒适性差, 发展除湿与降温耦 合的新型热泵空调系统可以实现能效的倍增 ${ }^{[53]}$, 这些 应用拓展所驱动的研发不但可以助力新兴领域的发展, 也是空调制冷技术未来发展的必由之路. 


\section{参考文献}

1 International Institute of Refrigeration. 38th Informatory Note on Refrigeration Technologies: The Role of Refrigeration in the Global Economy, 2019

2 Heath E A. Amendment to the Montreal protocol on substances that deplete the ozone layer (Kigali amendment). Int Legal Mater, 2017, 56: 193205

3 Wang R Z, Ding G L, Wu J Y. Principle and Technology of Refrigeration (in Chinese). Beijing: Science Press, 2003 [王如竹, 丁国良, 吴静怡. 制 冷原理与技术. 北京: 科学出版社, 2003]

4 Dai Y Q. LiBr Absorption Refrigeration Technology and Application (in Chinese). Beijing: China Machine Press, 1996 [戴永庆. 溴化锂吸收式制 冷技术及应用. 北京: 机械工业出版社, 1996]

5 Xu Z Y, Wang R Z. 11-Solar-powered absorption cooling systems. In: Advances in Solar Heating and Cooling. Cambridge: Woodhead Publishing, 2016. 251-298

6 Xu Z Y, Wang R Z. Absorption refrigeration cycles: Categorized based on the cycle construction. Int J Refrig, 2016, 62: 114-136

7 Wang R Z, Wang L W, Wu J Y. Theory and Application of Adsorption Refrigeration (in Chinese). Beijing: Science Press, 2007 [王如竹, 王丽伟, 吴静怡. 吸附式制冷理论与应用. 北京: 科学出版社, 2007]

8 Elbel S, Hrnjak P. Ejector refrigeration: An overview of historical and present developments with an emphasis on air-conditioning applications. International Refrigeration and Air Conditioning Conference, 2008

9 Sun D W, Eames I W. Performance characteristics of HCFC-123 ejector refrigeration cycles. Int J Energy Res, 1996, 20: 871-885

10 Qian S X, Yuan L F, Yan G, et al. State-of-the-art and prospects of elastocaloric cooling technology (in Chinese). J Refrig, 2018, 39: 1-12 [钱苏昕, 袁丽芬, 晏刚, 等. 弹热制冷技术的发展现状与展望. 制冷学报, 2018, 39: 1-12]

11 Li Z X, Li K, Shen J, et al. Progress of room temperature magnetic refrigeration technology (in Chinese). Acta Phys Sin, 2017, 66: 110701 [李振兴, 李珂, 沈俊, 等. 室温磁制冷技术的研究进展. 物理学报, 2017, 66: 110701]

12 Shi J, Han D, Li Z, et al. Electrocaloric cooling materials and devices for zero-global-warming-potential, high-efficiency refrigeration. Joule, 2019, 3: $1200-1225$

13 Tušek J, Engelbrecht K, Eriksen D, et al. A regenerative elastocaloric heat pump. Nat Energy, 2016, 1: 1-6

14 Moya X, Kar-Narayan S, Mathur N D. Caloric materials near ferroic phase transitions. Nat Mater, 2014, 13: 439-450

15 Kitanovski A, Plaznik U, Tomc U, et al. Present and future caloric refrigeration and heat-pump technologies. Int J Refrig, 2015, 57: 288-298

16 Bell L E. Cooling, heating, generating power, and recovering waste heat with thermoelectric systems. Science, 2008, 321: 1457-1461

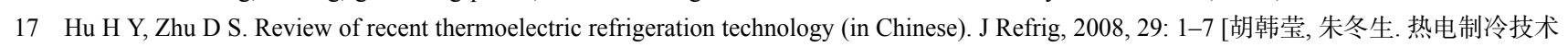
的研究进展与评述. 制冷学报, 2008, 29: 1-7]

18 Hossain M M, Gu M. Radiative cooling: Principles, progress, and potentials. Adv Sci, 2016, 3: 1500360

19 Zhai Y, Ma Y, David S N, et al. Scalable-manufactured randomized glass-polymer hybrid metamaterial for daytime radiative cooling. Science, 2017, 355: 1062-1066

20 Zhao D, Aili A, Zhai Y, et al. Subambient cooling of water: Toward real-world applications of daytime radiative cooling. Joule, 2019, 3: 111-123

21 Wang R, Xu Z, Hu B, et al. Heat pumps for efficient low grade heat uses: From concept to application. Therm Sci Eng, 2019, 27: 1-15

22 Jiang Y, Li Z, Chen X Y, et al. Liquid desiccant air-conditioning system and its application (in Chinese). J HV\&AC, 2004, 34: 88-97 [江亿, 李震, 陈晓阳, 等. 溶液除湿空调系列文章——溶液式空调及其应用. 暖通空调, 2004, 34: 88-97]

23 Wang R, Li X T, Shi W X, et al. Application of solution spray to heating ventilation and air conditioning systems: A review (in Chinese). J HV\&AC, 2016, 46: 63-69 [王瑞, 李先庭, 石文星, 等. 溶液喷淋在暖通空调中的应用综述. 暖通空调, 2016, 46: 63-69]

24 Zhou J M, Zhang X S, Sun B. Research progress on regenerative technology and energy analysis of solar liquid desiccant air-conditioning system (in Chinese). J Refrig, 2019, 40: 154-166 [周君明, 张小松, 孙博. 太阳能溶液除湿空调系统再生技术的研究进展与能耗分析. 制冷学报, 2019, 40: 154-166]

25 Jiang J J. Research on heat and mass transfer performance of internally-cooled liquid desiccant air handling process (in Chinese). Doctor Dissertation. Beijing: Tsinghua University, 2014 [江晶晶. 内冷型溶液除湿过程热湿传递性能研究. 博士学位论文. 北京: 清华大学, 2014]

26 Zhao Y, Ge T S, Dai Y J. Experimental investigation on silica gel coated heat exchanger cooling system driven by solar energy (in Chinese). J Eng Thermophys, 2014, 35: 223-227 [赵耀, 葛天舒, 代彦军. 基于太阳能能驱动的连续除湿换热器空调系统的实验研究. 工程热物理学报, 2014, 35: 223-227]

27 Tso C, Chao C Y. Activated carbon, silica-gel and calcium chloride composite adsorbents for energy efficient solar adsorption cooling and 
dehumidification systems. Int J Refrig, 2012, 35: 1626-1638

28 Seo Y K, Yoon J W, Lee J S, et al. Energy-efficient dehumidification over hierachically porous metal-organic frameworks as advanced water adsorbents. Adv Mater, 2012, 24: 806-810

29 Huang X, Qu Y, Di Y H. Application of multi-stage evaporative cooling air conditioning system to northwest China (in Chinese). J HV\&AC, 2004, 34: 67-71 [黄翔, 屈元, 狄育慧. 多级蒸发冷却空调系统在西北地区的应用. 暖通空调, 2004, 34: 67-71]

30 Xie X Y, Jiang Y, Liu S Q, et al. Design and development of an indirect evaporative water chiller (in Chinese). J HV\&AC, 2007, 37: 66-71 [谢晓 云, 江亿, 刘拴强, 等. 间接蒸发冷水机组设计开发及性能分析. 暖通空调, 2007, 37: 66-71]

31 Chen G B, Yan P D, Li J S. Research and development of Stirling cryogenic refrigerator (in Chinese). Cryogenics, 2006, 2006: 1-10 [陈国邦, 颜鹏 达, 李金寿. 斯特林低温制冷机的研究与发展. 低温工程, 2006, 2006: 1-10]

32 Chen G B, Tang K, Jin T. Research progress of thermoacoustic engine and thermoacoustic pulse tube refrigerator (in Chinese). Chin Sci Bull, 2004, 49: 825-830 [陈国邦, 汤珂, 金滔. 热声发动机及其驱动脉管制冷机研究进展. 科学通报, 2004, 49: 825-830]

33 Barreca A, Clay K, Deschenes O, et al. Adapting to climate change: The remarkable decline in the US temperature-mortality relationship over the twentieth century. J Polit Econ, 2016, 124: 105-159

34 Birol F. The future of cooling: Opportunities for energy-efficient air conditioning. International Energy Agency, 2018

35 Zhang H, Shao S, Xu H, et al. Free cooling of data centers: A review. Renew Sustain Energy Rev, 2014, 35: 171-182

36 Ebrahimi K, Jones G F, Fleischer A S. A review of data center cooling technology, operating conditions and the corresponding low-grade waste heat recovery opportunities. Renew Sustain Energy Rev, 2014, 31: 622-638

37 Wang R Z, Ge T S. Advances in Solar Heating and Cooling. Cambridge: Woodhead Publishing, 2016

38 Pesaran A A. Battery thermal management in EV and HEVs: Issues and solutions. Battery Man, 2001, 43: 34-49

39 Shen J, Zhang C, Liu S, et al. Development of multi-functional fresh-keeping device and experiment of cabbage vacuum pre-cooling (in Chinese). J Refrig, 2017, 38: 107-112 [申江, 张川, 刘升, 等. 多功能果蔬保鲜装置的研制及大白菜真空预冷实验. 制冷学报, 2017, 38: 107-112]

40 Tang J Y, Shao S Q, Xu H B, et al. Progress in research on the food quick-freezing method and simulation technology (in Chinese). J Refrig, 2018, 39: 1-9 [唐君言, 邵双全, 徐洪波, 等. 食品速冻方法与模拟技术研究进展. 制冷学报, 2018, 39: 1-9]

41 National Bureau of Statistics of China. China Statistical Yearbook (in Chinese), 2019 [中华人民共和国国家统计局. 中国统计年鉴, 2019]

42 Xu Z Y, Wang R Z, Yang C. Perspectives for low-temperature waste heat recovery. Energy, 2019, 176: 1037-1043

43 Wu D, Hu B, Wang R Z, et al. Preliminary study on high temperature heat pump system with water refrigerant (in Chinese). CIESC J, 2018, 69: 95100 [吴迪, 胡斌, 王如竹, 等. 采用自然工质水的高温热葲系统性能分析. 化工学报, 2018, 69: 95-100]

44 International Gas Union. World LNG Report, 2017

45 Gong M Q, Guo H, Sun Z H, et al. Advances in mobile natural gas mini-liquefiers (in Chinese). CIESC J, 2015, 66: 10-20 [公茂琼, 郭浩, 孙兆虎, 等. 小型可移动式天然气液化装置研究进展. 化工学报, 2015, 66: 10-20]

46 Gu A Z, Lu X S, Wang R S. Technology of Liquefied Natural Gas (in Chinese). Beijing: China Machine Press, 2004 [顾安忠, 鲁雪生, 汪荣顺. 液 化天然气技术. 北京: 机械工业出版社, 2004]

47 Cardella U, Decker L, Klein H. Roadmap to economically viable hydrogen liquefaction. Int J Hydrogen Energy, 2017, 42: 13329-13338

48 Zhu J B. Development of cryogenic refrigeration technology for deep space explorations (in Chinese). Spacecraft Recov \& Remote Sens, 2010, 31: 39-45 [朱建炳. 空间深空探测低温制冷技术的发展. 航天返回与遥感, 2010, 31: 39-45]

49 Gan Z H, Wang B, Liu D L, et al. Status and development trends of space mechanical refrigeration system at liquid helium temperature (in Chinese). J Zhejiang Univ (Eng Sci), 2012, 46: 2160-2177 [甘智华, 王博, 刘东立, 等. 空间液氦温区机械式制冷技术发展现状及趋势. 浙江大 学学报(工学版), 2012, 46: 2160-2177]

50 Zhang K H, Qiu L M, Gan Z H, et al. Advance in cryogenic system of cryocooled superconducting magnet (in Chinese). J Zhejiang Univ (Eng Sci), 2012, 46: 1213-1226 [张楷浩, 邱利民, 甘智华, 等. 制冷机传导冷却的超导磁体冷却系统研究进展. 浙江大学学报 (工学版), 2012, 46: 12131226]

51 Wang T T, Ren T, Ding G L, et al. Optimal design of room air conditioner with smaller diameter copper tube (in Chinese). Chin J Refrig Technol, 2012, 32: 1-4 [王婷婷, 任滔, 丁国良, 等. 小管径空调器的优化设计. 制冷技术, 2012, 32: 1-4]

52 Ge Y, Jiang W T. The research progress and application of the micro-channel heat exchanger (in Chinese). Chem Ind Eng Prog, 2016, 35: 10-15 [葛洋, 姜未汀. 微通道换热器的研究及应用现状. 化工进展, 2016, 35: 10-15]

53 McLinden M O, Brown J S, Brignoli R, et al. Limited options for low-global-warming-potential refrigerants. Nat Commun, 2017, 8: 1-9 


\title{
Air-conditioning and refrigeration: Current status and future perspectives
}

\author{
Zhenyuan $\mathrm{Xu} \&$ Ruzhu Wang ${ }^{*}$ \\ Institute of Refrigeration and Cryogenics, Shanghai Jiao Tong University, Shanghai 200240, China \\ * Corresponding author, E-mail: rzwang@sjtu.edu.cn
}

Air-conditioning and refrigeration systems are essential facilities of health care, transportation and food preservation, which make people able to live and work at the coldest and warmest climates in the planet. These technologies have been applied to a wide range of scenarios, including the distributed air-conditioning, food, medicine, health and sport for people's daily life, and centralized air-conditioning, heat pump and cryogenics in commercial and industrial applications.

In the near future, global warming, urbanization and pursuit of higher living standard will continue to push the demand of air-conditioning. Food preservation for the increasing global population and fresh food e-commerce require more cold storage. Space detection, low-temperature imaging and cryogenic medical treatment will push the cryogenics forward. Except for these listed applications, there are also many other driven forces for the next-step development of airconditioning and refrigeration, which make its future progress complicated. A comprehensive summary of the current status is necessary for air-conditioning and refrigeration, which will also provide us the basis to analyze its future perspectives.

Three typical air-conditioning and refrigeration technologies are introduced at first. These include the refrigeration/heat pump, temperature-humidity control and cryogenics. Vapor compression refrigeration, absorption refrigeration, adsorption refrigeration, ejector refrigeration, solid state refrigeration, refrigeration without thermodynamic cycles and heat pumps are introduced for the first topic, which focuses on the temperature manipulation in normal temperature range. Condensation dehumidification, solution dehumidification, solid desiccant dehumidification and evaporative cooling are introduced for the second topic, which focuses on the interaction of temperature and humidity of air. Gas liquefaction and cryocooler are introduced for the third topic, which focuses on the thermal energy removal under low temperature.

Conventional and emerging applications of these technologies are introduced afterwards. The refrigeration and dehumidification could support a wide range of application including air-conditioning, data center cooling, solar cooling, electrical vehicle thermal management and food/drug preservation. The applications of heat pumps include the clean heating supply and industrial heat recovery. The cryogenics could be applied for air liquefaction, liquefied natural gas, hydrogen storage, cryobiology/cryomedicine and big science project.

Based on the previous analysis, future challenges on efficiency enhancement, eco-friendly refrigeration and application promotion are presented at last. The efficiency enhancement is driven by the numerous equipments of air-conditioning and refrigeration in use, which consume a large portion of total power consumption of mankind. It could be achieved through the innovation on heat exchanger, thermodynamic cycle and intelligent control. The eco-friendly refrigeration is driven by the environmental protection policies. Low GWP and ODP refrigerants including HFOs and natural refrigerant will be effective solutions. Small-sized heat exchanger with less refrigerant charge is also important. The application promotion is driven by the fact that air-conditioning and refrigeration have already become the basic technology supporting the emerging technologies. Except for the traditional applications, the air-conditioning and refrigeration technologies are becoming fundamental technologies for many multidisciplinary fields, including the data center cooling, electrical vehicle thermal management, clean heating, industrial waste heat recovery, cryobiology/cryomedicine, and big science project.

refrigeration, air-conditioning, heat pump, cryogenics, cold storage

doi: 10.1360/TB-2020-0147 